$\begin{array}{cc}\text { ACADEMIA ROMÂNĂ } & \begin{array}{c}\text { Rev. Roum. Chim., } \\ \mathbf{2 0 2 1}, 66(1), 9-23\end{array} \\ \text { Revue Roumaine de Chimie } & \text { DOI: 10.33224/rrch.2021.66.1.01 } \\ \text { http://web.icf.ro/rrch/ } & \end{array}$

Review

\title{
NON-COVALENT INTERACTIONS EVIDENCED BY EPR SPECTROSCOPY IN CYCLODEXTRIN COMPLEXES
}

\author{
Iulia MATEI, Elena Irina POPESCU, Sorin MOCANU, Elena Nuşa HRISTEA, Florența SAVONEA, \\ Rodica BĂRĂȚOIU and Gabriela IONIȚA ${ }^{*}$ \\ Roumanian Academy, Institute of Physical Chemistry "Ilie Murgulescu", \\ Splaiul Independentei 202, Bucharest, 060021, Roumania
}

Received October 28, 2020

In this review are summarized studies, performed by researchers from the "Ilie Murgulescu" Institute of Physical Chemistry, involving electron paramagnetic resonance spectroscopy on noncovalent interactions. The review examines interactions between paramagnetic hosts and diamagnetic guests, diamagnetic hosts and paramagnetic guests, diamagnetic hosts and dual paramagnetic-fluorescent guests, interactions that accompany the formation of gel systems and interactions of fatty acid-like spin probes with proteins.

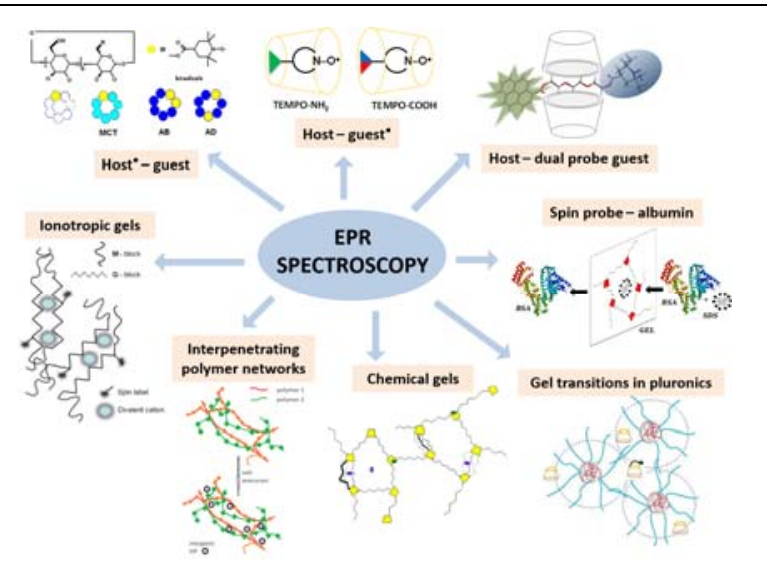

\section{INTRODUCTION}

Non-covalent interactions represent a broad type of physical interactions involving molecules and include hydrogen bonding, electrostatic dipole-dipole interactions, induction and dispersion van der Waals forces and hydrophobic interactions. Host-guest interactions involve (macro)molecules that can form complexes through a combination of non-covalent interactions and complementary structural features, and are, in many cases, the driving force for building supramolecular assemblies.
Over the last 50 years, supramolecular assemblies have been investigated by electron paramagnetic resonance (EPR) spectroscopy methods aiming at structural, dynamic and thermodynamic information. ${ }^{1-6}$ A large variety of systems resulted by molecular assembly through non-covalent interactions have been explored. For more than three decades, an interesting research topic regarded the dynamic characterisation of ionic and non-ionic surfactants ${ }^{6}$ in connection with their application as template agents in the preparation of mesoporous materials like silica or alumina. ${ }^{6-14}$ Less

\footnotetext{
${ }^{*}$ Corresponding author: ige@icf.ro
} 
represented were the EPR studies on host-guest interactions. The first report demonstrating that EPR spectroscopy is a suitable method to study hostguest interactions between $\beta$-cyclodextrin and the stable radical PROXYL (2,2,5,5-tetramethyl-1pyrrolidinyloxy), in water, was published in 1975 and belongs to Rassat et al. ${ }^{15}$ It was followed by a group of papers published in the late 80's and early 90's. ${ }^{16-20}$ These studies describe interactions between diamagnetic hosts and stable free radicals from the PROXYL and TEMPO $(2,2,6,6-$ tetramethyl-1-piperidinyloxy) series. Later, the interaction between cyclodextrins and less stable radicals generated in situ was investigated. ${ }^{21}$

Aligning to this particular research direction, our studies refer to host-guest interactions involving cyclodextrins or cucurbiturils as hosts, interactions of paramagnetic probes (spin probes) with albumins, and the use of spin probes and spin labels to monitor the formation and properties of different gels. In this review, we provide a summary of EPR studies on different supramolecular assemblies, performed over the course of the past 15 years by researchers at the "Ilie Murgulescu" Institute of Physical Chemistry, some in collaboration with scientists from other laboratories.

\section{Host-guest complexes of monoradicals}

These studies have been concerned with the behaviour of nitroxide-type spin probes in cyclodextrin or cucurbituril solution. Thus, the interaction of stable radicals from the TEMPO and PROXYL classes (Fig. 1) with natural or derivatized cyclodextrins has been analysed using EPR spectroscopy, ${ }^{22-24}$ as well as a combination of EPR and circular dichroism. ${ }^{25}$ Host-guest complexes of a series of mono- and poly-TEMPO radicals with cucurbit[6]uril $(\mathrm{Q}[6])$ have also been investigated by EPR spectroscopy. ${ }^{26}$ In addition to commercially available cyclodextrins $[\alpha-, \beta-, 2-$ hydroxypropyl- $\beta$ - (HPB), methyl- $\beta$ - (MCD) and $\gamma$ $\mathrm{CD}],{ }^{25}$ polymeric, water-soluble $\beta$-CD-based nanocapsules $\left[(\mathrm{CDS})_{\mathrm{n}}\right]$ obtained via a disulphide cross-linking process were used..$^{22,25}$ The latter materials (average diameter $30 \mathrm{~nm}$ ) form spontaneously during air oxidation of aqueous suspensions of per-thiolated $\beta-\mathrm{CD} .^{27}$

The stability of host-guest complexes is determined, in the first instance, by the geometric features of the host, namely the cavity size that depends on the number of repeating units. ${ }^{28,29}$ The inclusion process occurs with desolvation of both the host cavity and the guest molecule, and therefore hydrophobic/hydrophilic groups in the structure of the host and guest can significantly affect complexation.

Using these various spin probes and cyclodextrins, it was possible to evidence different complexation modes of hydrophobic guests, depending on the polarity and geometrical features of the interacting species. Inclusion of the nitroxide group into the cyclodextrin cavity mainly affects two EPR parameters of the probe: the nitrogen hyperfine splitting constant $\left(a_{N}\right)$, which reports on the polarity around the probe (e.g., water $v s$. cavity), and the spectral linewidth, which depends on the rate of tumbling (rotational correlation time, $\tau$ ). As a common behaviour, the tumbling of the spin probe is slowed upon complexation. The EPR spectrum of a spin probe in solution of water-soluble host is a sum of contributions from the diffusion of the whole complex and of the free spin probe. In particular cases, it is possible to clearly observe the two spectral components (Fig. 2), and simulation of the spectra provides the EPR parameters of each component. $^{22}$

The decrease in the $a_{N}$ value upon complexation of a nitroxide radical with a host is observed only for an inclusion complex geometry in which the nitroxide group is located inside the cavity. In the case of the interaction of functionalised TEMPO derivatives like 4-carboxy-TEMPO and 4-aminoTEMPO with cyclodextrins, it was observed that the inclusion process depends on the solution $\mathrm{pH}$. This aspect has been discussed in detail in a recent study that combines EPR spectroscopy, circular dichroism spectroscopy and molecular modeling. ${ }^{25}$ Compared to water, the cyclodextrin cavity has a relatively non-polar character, therefore it will readily accommodate non-polar molecules/molecular fragments rather than ionic species. The complexation of the TEMPO radical is independent on $\mathrm{pH}$ (Fig. 3), and this is understandable as no ionic group is present in the structure.

Depending on the $\mathrm{pH}$ value, the functionalised spin probes 4-carboxy-TEMPO and 4-aminoTEMPO can be found in either neutral or ionic form. Evidently, the neutral form favours inclusion of the nitroxide group in the cavity, while the ionic form weakens the inclusion complex (Fig. 4). 


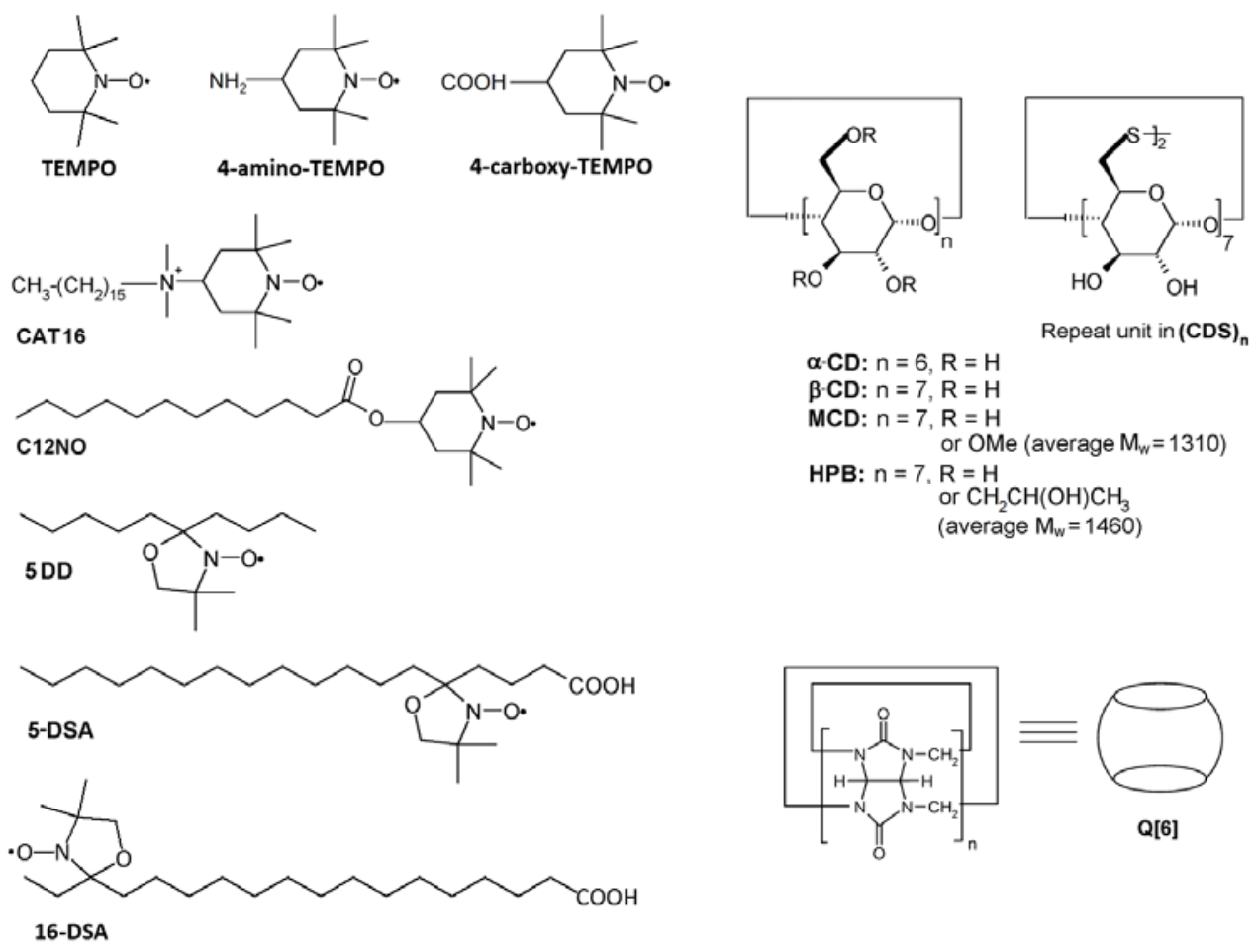

Fig. 1 - Structures of nitroxide radicals, cyclodextrins and cucurbit[6]uril.

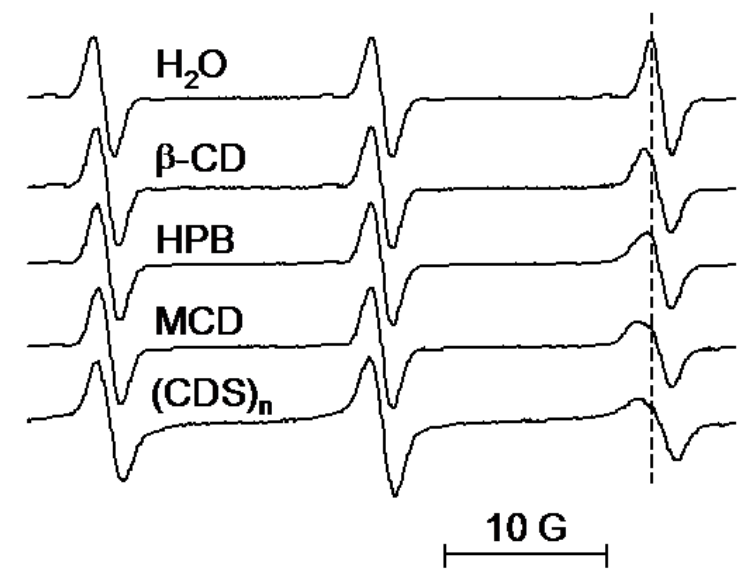

Fig. 2 - The EPR spectra of TEMPO in water and in $\beta-C D, H P B, M C D$ and $(C D S)_{n}$ solutions. Concentration of each cyclodextrin was $1 \mathrm{mM}$ (reproduced from ref. $^{22}$ ).

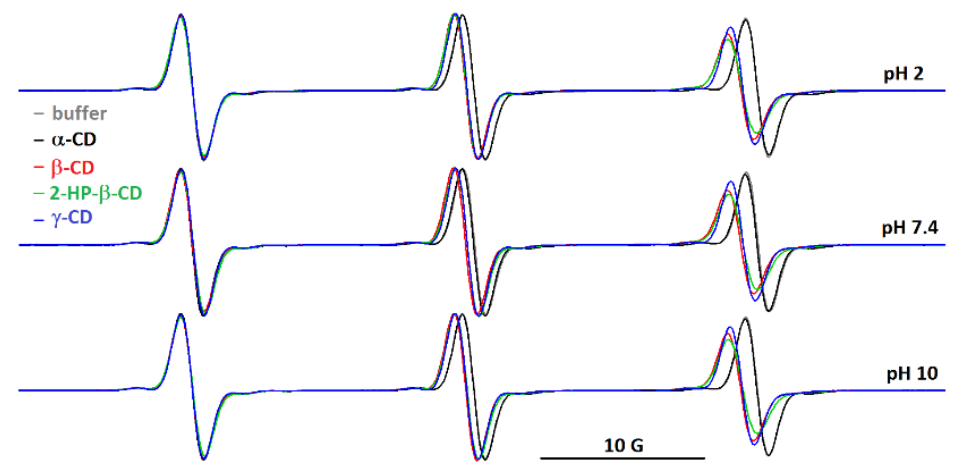

Fig. 3 - The EPR spectra of TEMPO in $10^{-2} \mathrm{M}$ cyclodextrin solution at different $\mathrm{pH}$ values (reproduced from ref. ${ }^{25}$ ). 


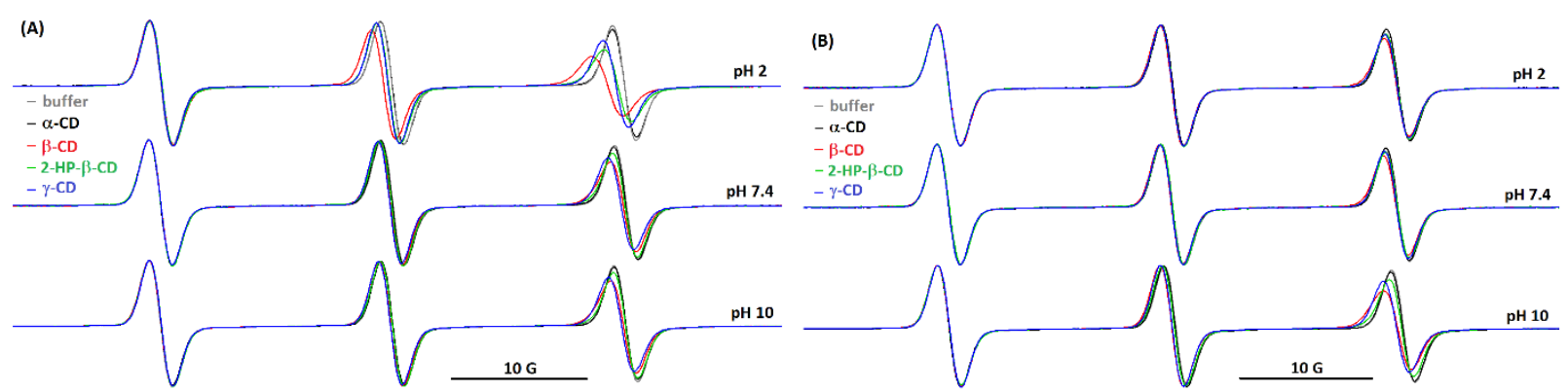

Fig. 4 - The EPR spectra of (A) 4-carboxy-TEMPO and (B) 4-amino-TEMPO in 10-2 M cyclodextrin solution at different $\mathrm{pH}$ values (reproduced from ref. $^{25}$ ).
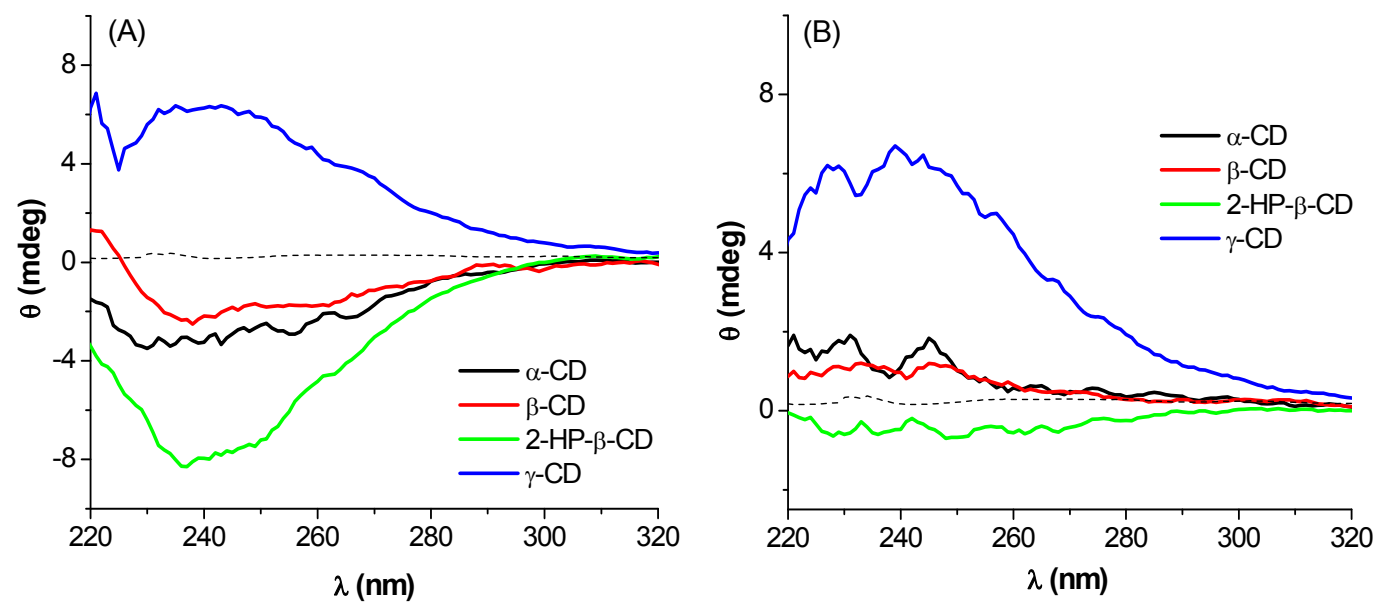

Fig. 5 - Induced circular dichroism spectra of (A) 4-carboxy-TEMPO at pH 2 and (B) 4-amino-TEMPO at pH 10, in the absence (dashed lines) and in the presence of cyclodextrins. [4-carboxy-TEMPO] $=[4$-amino-TEMPO $]=7 \times 10^{-4} \mathrm{M},[\mathrm{CD}]=10^{-2} \mathrm{M}$ (reproduced from ref. $^{25}$ ).

Interestingly, complexation of 4-carboxyTEMPO and 4-amino-TEMPO determines the appearance of induced circular dichroism signals of the neutral species that vary in sign and intensity as a function of guest substituent and cyclodextrin type (Fig. 5). By correlating the EPR and circular dichroism data to molecular modeling results, the geometries of the inclusion complexes can be predicted. ${ }^{25}$ The analysis of the changes in EPR parameters, combined with data provided by other techniques, can therefore lead to information on the geometric orientation of paramagnetic groups in the complexes.

Similarly, we investigated the interaction of a new series of nitroxide radicals that contain functional groups able to generate hydrogen bonds (urea or amine derivatives) with the first term of the cucurbiturils family, Q[6]. ${ }^{26}$ These synthetic hosts possess a cavity marked by methylene groups and decorated on the rims with carbonyl groups, ${ }^{28}$ which favour the formation of complexes through hydrophobic interactions, in the case of hydrophobic guests, or ion-dipole interactions, in the case of metal cations and protonated alkyl or aryl amines. ${ }^{30}$ Previously, interactions of organic radicals with cucurbiturils have been reported by other groups, stressing that the geometry of the complex is determined by the size of the host. ${ }^{30-32}$ The portal diameter of $\mathrm{Q}[6]$ is comparable to that of $\alpha-\mathrm{CD}$, while the interior diameter has an intermediary value between those of $\alpha$-CD and $\beta$-CD. ${ }^{3}$ The analysis of the EPR parameters of the functionalized nitroxides in interaction with Q[6] indicated small changes in $a_{N}$ and slower tumbling, which led us to conclude that the $\mathrm{NH}$ groups of the radicals interacted with the carbonyl groups of Q[6] via hydrogen bonding. ${ }^{26}$

Association constants of nitroxide-type radicals with $\mathrm{CDs}$ or $\mathrm{Q}[6]$ were evaluated assuming a linear dependence of $\tau$ on the concentration of complex in solution. In the case of cyclodextrin complexes, the values are in the range $10^{2}-10^{4} \mathrm{M}^{-1},{ }^{22,25}$ while in the case of complexes with $\mathrm{Q}[6]$, the association constants range between $10-10^{2} \mathrm{M}^{-1},{ }^{26}$ indicating a weaker interaction. 


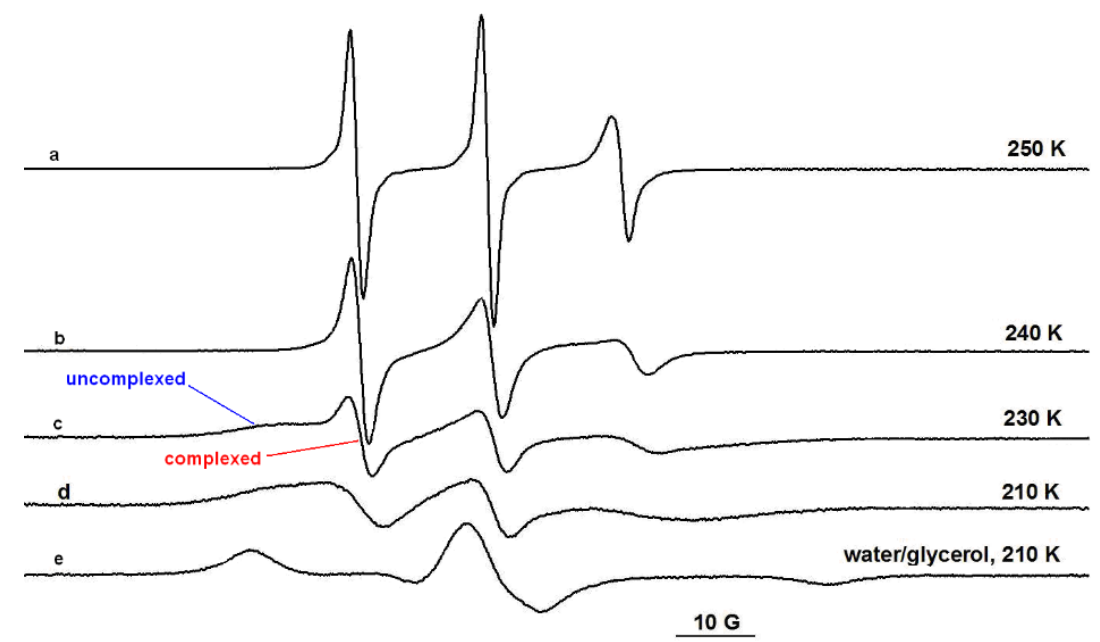

Fig. 6 - The EPR spectra of TEMPO in 8:2 (w/w) water:glycerol solution of $\beta$-CD $\left(10^{-2} \mathrm{M}\right)$ at different temperatures (a-d) and at 210 $\mathrm{K}$ in the absence of cyclodextrin (e).

\section{Inclusion complexes in aqueous glycerol below room temperature}

The analysis of the EPR spectra of TEMPO radicals in cyclodextrin solution below room temperature provides supplementary dynamic information $^{23}$ that can be further exploited to evidence host-guest interactions in more complex systems and in gels. EPR measurements at low temperature require the preparation of samples in aqueous glycerol. At room temperature, the spectral changes induced by the presence of cyclodextrin are smaller in water:glycerol than in water. Below room temperature, however, the EPR spectra of spin probes become more sensitive to complexation.

In the absence of cyclodextrin, the EPR spectra of spin probes at temperatures in the range 250-210 $\mathrm{K}$ show progressive reduction in the tumbling rate (Fig. 6). The freezing of molecular mobility (powder pattern) on the EPR time scale depends on the molecular structure of the spin probe, as this point was reached at slightly different temperatures in the range $230-210 \mathrm{~K} .{ }^{23}$ This result suggests that rotational diffusion depends not only on local viscosity, but also on specific interactions between spin probe and environment. The rotational diffusion of TEMPO slows down at a lower temperature compared to other spin probes. At 210 $\mathrm{K}$, all spin probes used in the study show powder pattern EPR spectra.

The presence of two components, assigned to free and complexed TEMPO, is clearly visible in the spectra in Fig. 6. Interestingly, the spectrum at 210 $\mathrm{K}$ is dominated by the component that tumbles much faster than pure TEMPO under the same conditions. This suggests that the tumbling rate of complexed TEMPO is faster than that of free TEMPO. This is a rather unusual observation, as the formation of host-guest complexes normally results in the reduction of the tumbling rate. It implies that, as the solution vitrifies, the environment inside the cyclodextrin cavity remains quite mobile. Nevertheless, vitrification could occur with poor homogeneity, and thus the formation of aggregates or pools of fluid trapped inside the vitreous phase cannot be ruled out. To unambiguously prove that the changes in the EPR spectra are due to complexation and not to heterogeneity artefacts, we carried out competition experiments in the presence of adamantanol (AdOH) (Fig. 7). Adamantane derivatives possess high affinity for the $\beta-C D$ cavity $^{33}$ and are thus expected to effectively compete with TEMPO. In the presence of this competing guest, the EPR spectrum of the TEMPO/ $\beta-C D$ solution is indistinguishable from that of free TEMPO, confirming the displacement of TEMPO from the $\beta$-CD cavity by $\mathrm{AdOH}$.

\section{Host-guest complexes involving biradicals and poliradicals}

The advantage of using biradicals and poliradicals to confirm the formation of host-guest complexes lies in their additional spectral features arising from spin-spin interactions, which provide information on the distance between the paramagnetic moieties. Experimental data obtained from X-band continuous wave EPR measurements on biradical systems can be used if the distance between the radical moieties linked through a bridge is up to $2 \mathrm{~nm}$, while the double electron-electron 
resonance (DEER) EPR method allows determination of spin-spin distances between 2 and $15 \mathrm{~nm} \cdot{ }^{34}$ In case of supramolecular interactions with other species, the nitroxide groups from biradical or poliradical structures may be shielded from each other, which leads to the observation of three-line EPR spectra characteristic to nitroxide monoradicals. We reported several EPR studies on host-guest interactions involving, as guests, the biradicals and poliradicals shown in Fig. $8 .^{26,35-37}$ The biradicals in series $\mathbf{A}$ and $\mathbf{C}$ possess higher molecular flexibility compared with those in series $\mathbf{B}$, which bear rigid aromatic linkers.

In aqueous solution, the biradicals from series $\mathbf{A}$ show five-line EPR spectra due to the exchange interaction between the two paramagnetic fragments linked by the polyether chain. The intensity of the lines attributed to spin-spin interactions depends on the length and flexibility of the polyether chain. It was found that the term P3T2 in this series shows the most intense exchange interaction lines. ${ }^{35,36}$ EPR studies regarding complexation of radicals from series $\mathbf{A}$ and $\mathbf{B}$ with cyclodextrins $(\alpha-, \beta-C D$ and $\mathrm{HPB})^{35,37}$ and of radicals $\mathbf{C}$ with cucurbituril $\mathrm{Q}[6]^{26}$ have been reported. By monitoring the changes in the intensity of the exchange interaction lines, it was possible to evidence and further evaluate the equilibrium ratio and association constants, which fall in the range $10^{2}-10^{3} \mathrm{M}^{-1}$ for $1: 1$ complexation and $10^{4}-10^{5} \mathrm{M}^{-2}$ for $1: 2$ complexation.

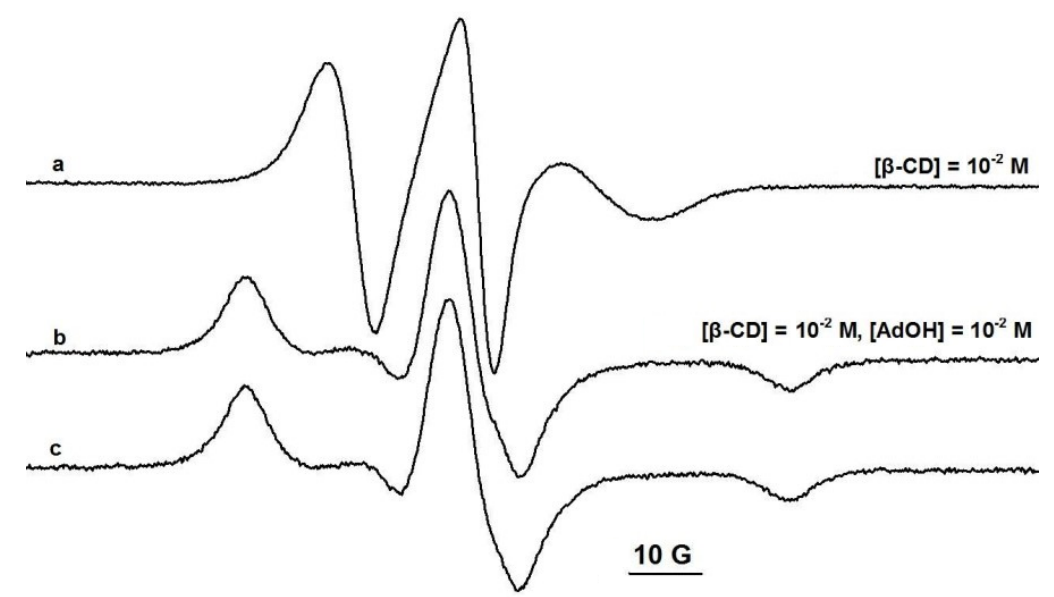

Fig. 7 - Competition experiment: EPR spectra of TEMPO at $210 \mathrm{~K}$ in 8:2 (w/w) water:glycerol in the presence of (a) $\beta-\mathrm{CD}$, (b) $\beta$-CD + adamantanol, and (c) without additives (reproduced from ref. $^{23}$ ).<smiles>CC1(C)CC(OCCOCCOC(=O)C2CC(C)(C)N([O-])C(C)(C)C2)CC(C)(C)N1[O-]</smiles>

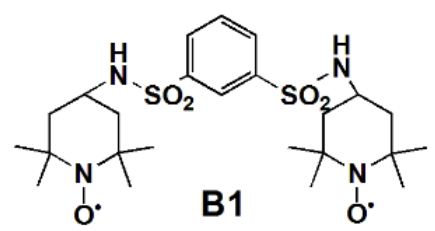<smiles>CC1(C)CC(NS(=O)(=O)c2ccc(-c3ccc(C(=O)O[Na])cc3)cc2)CC(C)(C)N1[O]</smiles>

B3

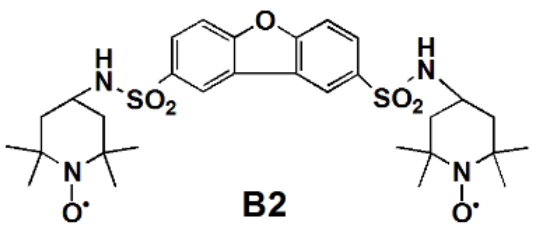

C1<smiles>CC1(C)CC(NC(=O)NCCNC(=O)NC2CC(C)(C)N([O])C(C)(C)C2)CC(C)(C)N1[O]</smiles><smiles>CC1(C)CC(NC(=O)NC2CC(C)(C)N([O])C(C)(C)C2)CC(C)(C)N1[O]</smiles>

C2<smiles>CC1(C)CC(NC(=O)NCCN(CCNC(=O)NC2CC(C)(C)N([O-])C(C)(C)C2)CCNC(=O)NC2CC(C)(C)N([O-])C(C)(C)C2)CC(C)(C)N1[O-]</smiles>

Fig. 8 - Structures of nitroxide bi and poliradicals. 


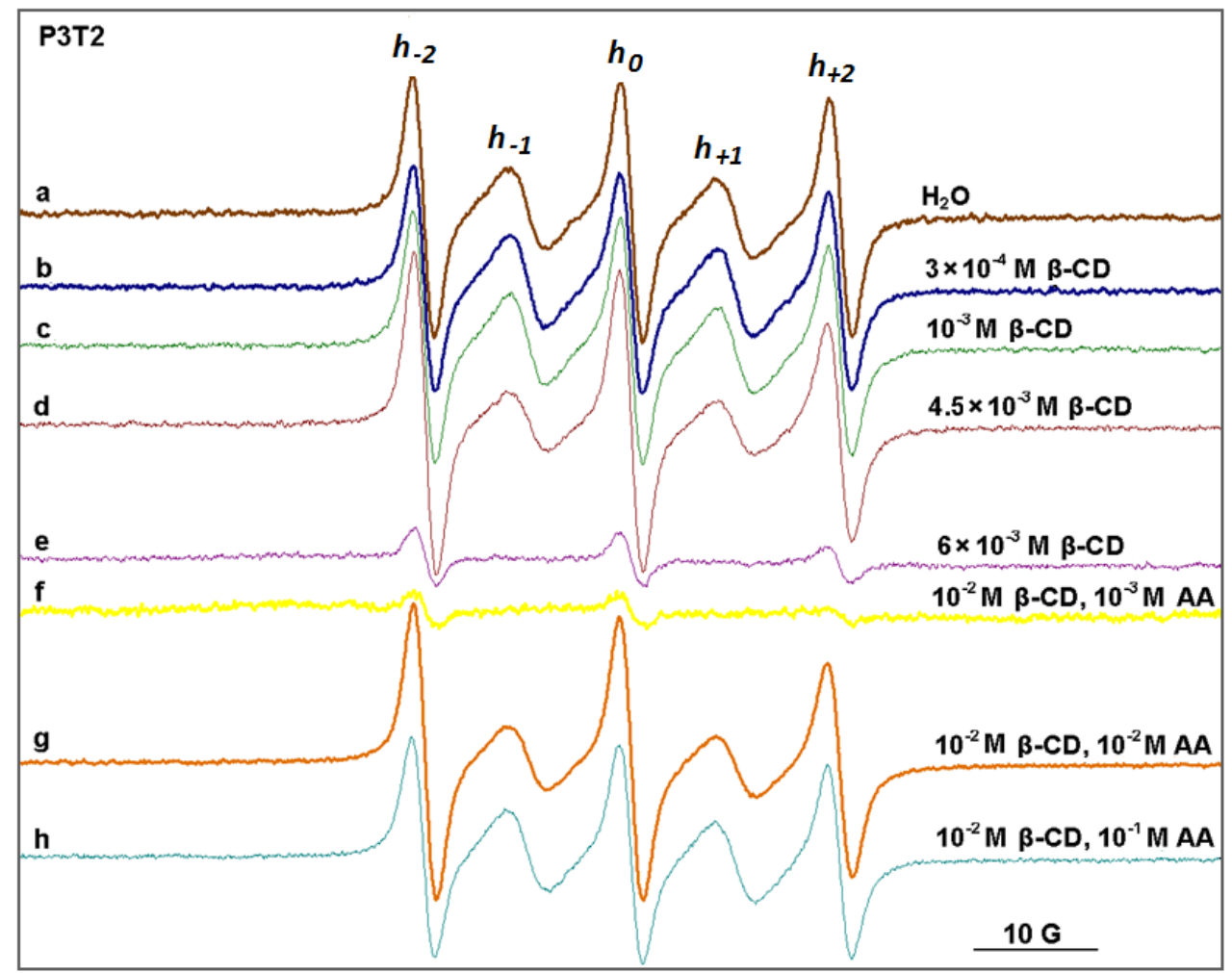

Fig. 9 - The EPR spectra of P3T2 in water (a), in the presence of increasing concentrations of $\beta$-CD (b-e), and in mixtures $\beta-C D+1$-adamantylamine (f-h) (reproduced from ref. ${ }^{35}$ ).

The EPR spectra of the P3T2 biradical in aqueous solution and in the presence of $\beta-\mathrm{CD}$ are shown in Fig. 9. The high field line $\left(h_{+2}\right)$ decreases upon addition of cyclodextrin due to the slower tumbling of the nitroxide moiety caused by complexation. The exchange lines $\left(h_{-1}\right.$ and $\left.h_{+1}\right)$ also decrease in intensity with increasing $\beta-\mathrm{CD}$ concentration, until they completely disappear at $[\beta-\mathrm{CD}] \sim 6 \times 10^{-3} \mathrm{M}$ (Fig. 9e). At this concentration, complexation of one radical moiety by the $\beta$-CD cavity prevents the exchange interaction. At higher $\beta-C D$ concentration, the solution becomes turbid and a precipitate appears, determining the drastic reduction of the overall intensity in the EPR spectrum of the solution. ${ }^{35}$ Adding a competing guest, 1-adamantylamine (AA), results in the solubilisation of the precipitate and the reappearance of the five-line EPR spectrum (Fig. 9 g, h).

In the case of complexation with $\alpha-C D$, the presence of the five-line spectrum was observed up to a higher cyclodextrin concentration $(1 \mathrm{M})$, at which only the three-line spectrum was recorded. However, this effect is in part due to the increased viscosity of the environment. In the case of HPB, complexation also occurs at lower cyclodextrin concentration $\left(10^{-2} \mathrm{M}\right)$. In the latter case, the separation of the complex as a solid precipitate was not observed.

For bi and poliradicals in series $\mathbf{B}$ and $\mathbf{C}$, the exchange interaction lines are less intense in water, indicating a smaller frequency of collisions between the paramagnetic moieties. Complexation with $\beta$ $\mathrm{CD}$ and $\mathrm{Q}[6]$ is also associated with the decrease in exchange lines intensity as the host concentration increases. ${ }^{26,37}$

\section{Dual molecular probes}

The EPR analyses of supramolecular systems offer valuable information, yet a more in-depth understanding can be gained by combining EPR spectroscopy with other spectral methods. We have shown that, by combining EPR and circular dichroism spectroscopies, we can obtain a clearer picture on the inclusion of TEMPO radicals in the cyclodextrin cavity. ${ }^{25}$ Another approach is to use molecular probes bearing two different sensing moieties, one paramagnetic and one fluorescent, to investigate supramolecular complexes. Literature reports on such dual molecular probes, and their properties have been mainly analysed in respect to the quenching effect exerted by the nitroxide group on the fluorescence emission. ${ }^{38,39}$ 
Our research on the topic began by studying the behaviour of a simple dual molecular probe with a relatively rigid structure, dansyl-TEMPO (DT) ${ }^{40}$ in the presence of cyclodextrin. ${ }^{41}$ The analysis of the fluorescence and EPR spectra of DT in $\beta-C D$ solutions led to the conclusion that complexation occurs mainly with the inclusion of the dansyl moiety in the $\beta-C D$ cavity. The fluorescence intensity of DT is weak, due to the quenching effect of the nitroxide group in close proximity to the dansyl fluorophore. Inclusion complexation of either one of the two sensing groups of DT diminishes quenching. By increasing the $\beta-C D$ concentration, the enhancement of the DT fluorescence intensity was observed, accompanied by a blue shift of the emission maximum of dansyl, indicating that the fluorophore is located in a less polar environment, thus proving its inclusion in the cyclodextrin cavity. Moreover, the value of the hyperfine splitting constant, $\mathrm{a}_{\mathrm{N}}$, does not vary significantly with the $\beta-C D$ concentration. Corroborating these data, we concluded that the TEMPO moiety is exposed to the aqueous environment, while the cyclodextrin cavity includes preferentially the dansyl moiety.

This study underpinned our motivation to obtain new series of dual molecular probes bearing a paramagnetic moiety coupled with a fluorophore by means of flexible linkers of variable length (Fig. 10). By introducing a bridge between the two moieties, it was possible to modulate the influence of the nitroxide on the emissive properties of the probe. A first series of such dual molecular probes was synthesized by connecting the paramagnetic TEMPO moiety to the fluorescent pyrene moiety via oligoethylene glycol chains $\left(\mathbf{P y}(\mathbf{E G})_{\mathbf{n}} \mathbf{T}\right) \cdot{ }^{42}$ In a second series of probes, TEMPO was linked to the fluorescent dansyl moiety by alkyl chains $\left(\mathbf{D A}_{1 . n} \mathbf{T}\right){ }^{43}$ In addition to these dual probes, monopyrene $^{42}$ and mono- ${ }^{43,44}$ and bis-dansyl ${ }^{45}$ fluorescent derivatives were also prepared. All series of probes were investigated in interaction with cyclodextrins by fluorescence and EPR spectroscopies. The analysis of the spectral features in solution and upon complexation revealed different behaviours of the probes.

The choice of linking the pyrene fluorophore to the TEMPO moiety by oligoethylene glycol chains was made taking into account the emissive properties of pyrene ${ }^{46}$ and our findings on the EPR properties of the P3T2 biradical. ${ }^{35}$ It is well known that the fluorescence spectrum of pyrene is characterised by a vibrational structure sensitive to local changes in polarity and dynamics. ${ }^{46}$ The fluorescence band of the $\mathbf{P y}(\mathbf{E G})_{\mathbf{n}} \mathbf{T}$ dual probes does not show a vibrational structure, and the fluorescence quantum yield $(\Phi)$ of the probes does not follow a linear variation with the chain length (Fig. 11). This irregular trend is due to different proximities between the fluorophore and the nitroxide quencher, determined by the gauche or anti arrangement around $\mathrm{C}-\mathrm{C}$ and $\mathrm{C}-\mathrm{O}$ bonds and by the length of the oligoethylene glycol chain. The $\Phi$ values of $\mathbf{P y}(\mathbf{E G})_{\mathbf{n}} \mathbf{T}$ probes range from 0.23 for $\mathrm{n}=6$ to 0.05 for $\mathrm{n}=2$.

This non-linear behaviour of EPR and fluorescence parameters can provide distinct information in complex systems in which hostguest interactions occur, ${ }^{42}$ and in block copolymer micelles where the hydrophilic/hydrophobic properties are non-uniform. ${ }^{47}$

The interaction between $\mathbf{P y}(\mathbf{E G})_{\mathbf{n}} \mathbf{T}$ dual probes and $\beta-C D$ was elucidated by following the changes in the EPR and fluorescence spectral features and parameters. At high $\beta-C D$ concentration, the appearance of the vibrational fine structure of pyrene emission was observed. The EPR parameters of the probes in the presence of $\beta-C D$ evidenced a different complexation behaviour along the series. The highest variation of $a_{N}$ upon complexation was observed for the short chain probes $(n=1,2)$, which indicated the inclusion of the TEMPO moiety in the $\beta-C D$ cavity in the case of these probes. Corroborating also with timeresolved fluorescence data, for the longer chain probes we predicted the formation of both inclusion and encapsulation complexes of different geometry and stoichiometry (Fig. 12).

The $\operatorname{Py}(\mathbf{E G})_{\mathbf{n}} \mathbf{T}$ dual probes were also used to investigate the micelle-to-gel phase transition occurring in systems containing pluronic F127, in the absence and in the presence of HPB. ${ }^{47}$ It was shown that the structural particularities of the probes markedly influenced the probe response. The analysis of the fluorescence and EPR spectra recorded in a temperature range around the micelle-to-gel transition temperature revealed the fact that only the EPR parameter $a_{N}$ was sensitive to the polarity changes accompanying the phase transition. The local information provided by EPR spectroscopy was then correlated with the global information provided by rheological parameters to reveal that gelation involves continuous molecular reorganization processes occurring in the temperature interval of the gel phase. 


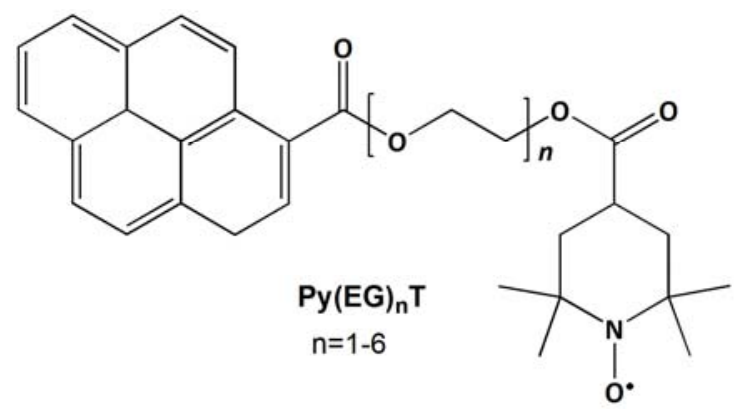<smiles>CN(C)c1cccc2c(S(=O)(=O)NCCNC(=O)C3CC(C)(C)N([O])C(C)(C)C3)cccc12</smiles>

Fig. 10 - Dual paramagnetic-fluorescent molecular probes.

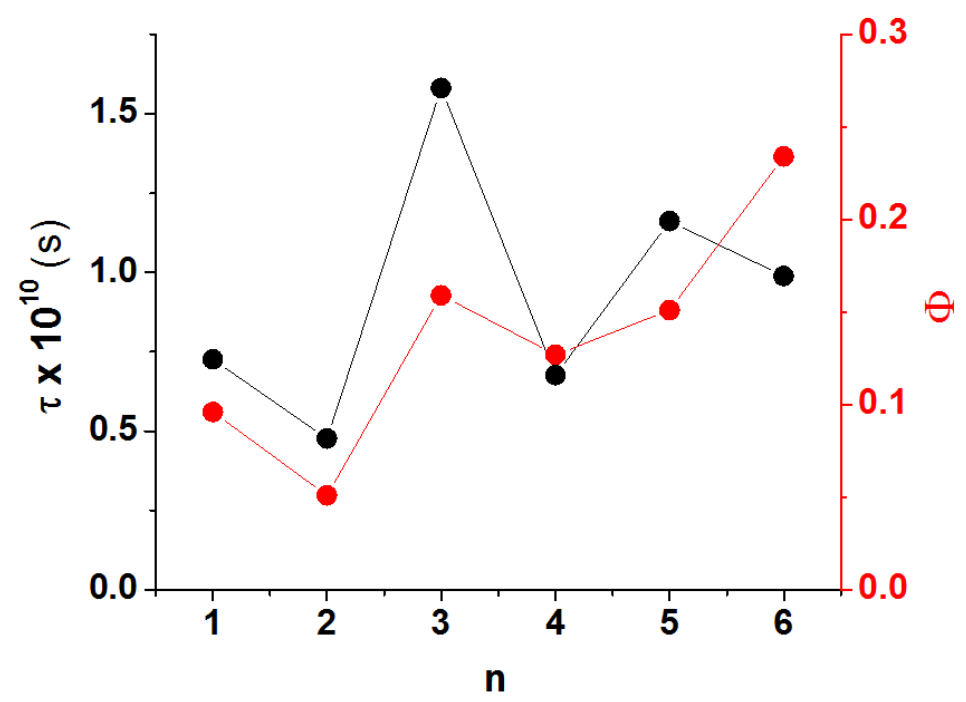

Fig. 11 - The variation of the rotational correlation time $(\tau)$ and fluorescence quantum yield $(\Phi)$ of the $\mathbf{P y}(\mathbf{E G})_{\mathbf{n}} \mathbf{T}$ dual probes with the length of the oligoethylene glycol chain (n) (reproduced from ref. ${ }^{42}$ ).

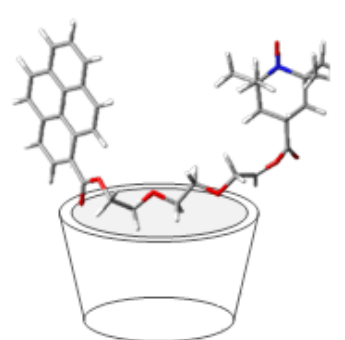

$1: 1$

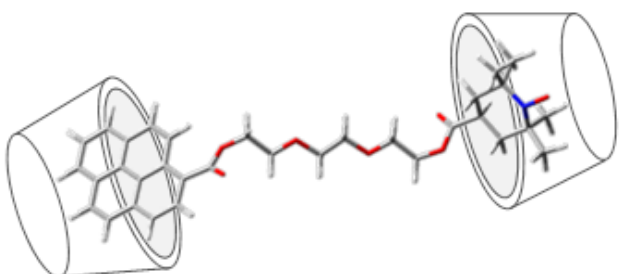

$1: 2$

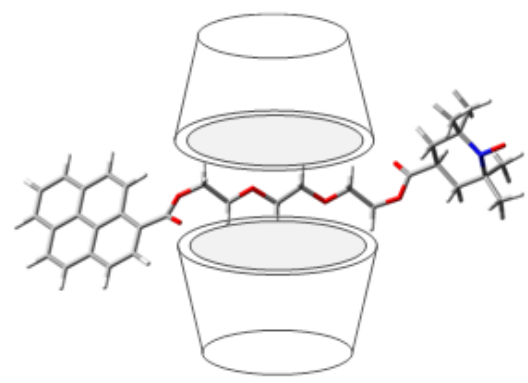

$1: 2$

Fig. 12 - Schematic representation of the geometries of the inclusion and encapsulation complexes of $\mathrm{Py}(\mathrm{EG})_{\mathrm{n}} \mathrm{T}$ dual probes with $\beta-\mathrm{CD}$ (reproduced from ref. ${ }^{42}$ ).

Differently from the case of $\mathbf{P y}(\mathbf{E G})_{\mathbf{n}} \mathbf{T}$, the quenching effect of the TEMPO moiety on the dansyl fluorophore, in the case of the $\mathbf{D A}_{\mathbf{1 . n}} \mathbf{T}$ dual probes, decreases quasi-linearly with the length of the alkyl linker (Fig. 13). Nevertheless, it must be noted that, due to the flexibility of the alkyl chain, an increased linker length may favour bended conformations that bring the two sensing groups in close proximity.
The probes $\mathbf{D A}_{1 . \mathbf{n}} \mathbf{T}$ interact with $\beta-\mathrm{CD}$ in solution by inclusion of the dansyl moiety in the cyclodextrin cavity, as the $a_{N}$ value of the probes decreases with no more than $0.1 \mathrm{G}$ in the presence of $\beta-C D$, while the dansyl fluorescence is greatly enhanced and shifts hypsochromically upon complexation. $^{43}$ The values of the association constants are of the order $10^{2} \mathrm{M}^{-1}$ for $1: 1$ complexes, in agreement with the association constant found for the complexation of DT with $\beta-C D{ }^{41}$ 


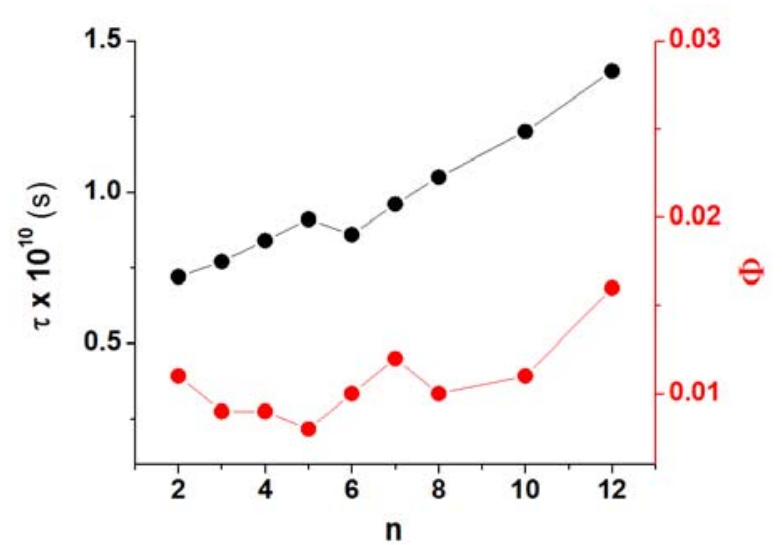

Fig. 13 - The variation of the rotational correlation time $(\tau)$ and fluorescence quantum yield $(\Phi)$ of the $\mathbf{D A}_{\mathbf{1 . n}} \mathbf{T}$ dual probes with the length of the alkyl chain (n) (adapted from ref. ${ }^{43}$ ).

For both series of dual probes, $\mathbf{P y}(\mathbf{E G})_{\mathbf{n}} \mathbf{T}$ and $\mathbf{D A}_{1 . \mathrm{n}} \mathbf{T}$, the host-guest interaction with cyclodextrins was also shown to occur in hydrogels that contain cyclodextrins in their covalent network. ${ }^{42,43}$

\section{Spin-labelled cyclodextrins}

The results presented above refer to the general case of the interaction between a paramagnetic guest and a diamagnetic host. Attaching a paramagnetic moiety to the host macromolecule makes it possible to expand the scope of EPR studies to complexes of spin-labelled hosts with unlabelled guests. Except for one early study, which did not probe host-guest complexation, ${ }^{48}$ spin-labelling of cyclodextrins started to present interest during the last 15 years. To date, only few studies have reported the synthesis of spin-labelled cyclodextrins (SL-CDs). One of these recent studies was reported by Ionita and Chechik (York University), ${ }^{49}$ and described the synthesis and inclusion properties of three SL-CDs (Fig. 14).

This work was followed by two other studies ${ }^{24,50}$ reporting on the interaction of SL-CDs with low and high molecular weight compounds by using continuous wave and pulsed EPR spectroscopies. Cyclodextrins accommodate in their cavities phenolphthalein and 1-adamantylamine, which are characterised by high values of the association constants $\left(\sim 10^{4} \mathrm{M}^{-1}\right) .{ }^{51}$ In the case of SL-CDs, the association constants of these guests are two orders of magnitude lower. ${ }^{50}$ Indeed, X-band continuous wave EPR measurements have indicated that SLCDs are characterised by weaker association properties. $^{49,50,52}$

The high affinity of adamantane derivatives for the cyclodextrin cavity can be exploited towards building a cyclodextrin assembly. As such, dendrimers were functionalised with several adamantane groups following literature procedures. ${ }^{50}$

The article reporting the synthesis of the three SL-CDs was soon followed by a study reported by Bardelang et al., ${ }^{53}$ in which the authors described the synthesis of a mono spin-labelled permethylated derivative and analysed the self-inclusion process of the paramagnetic moiety covalently attached to the cyclodextrin unit. ${ }^{53-55}$

Host-guest interactions of cyclodextrins have also been investigated by the electron spin-echo envelope modulation (ESEEM) method of EPR spectroscopy, in collaboration with prof. D. Goldfarb and prof. V. Chechik. ${ }^{24}$ This was the first study reporting on the application of a pulsed method, in particular ESEEM, to investigate hostguest interactions. The modulation depth obtained by analysis of the ESEEM traces corresponding to the free paramagnetic guest (4-carboxy-TEMPO) and to its complex with cyclodextrin showed differences. Inclusion into the cavity corresponds to exposure to a less hydrated environment and, in consequence, to a smaller modulation depth. The addition of adamantanol as competing guest increases the modulation width back to its original value, which is consistent with the displacement of 4-carboxy-TEMPO from the cyclodextrin cavity by the competing guest of higher affinity.
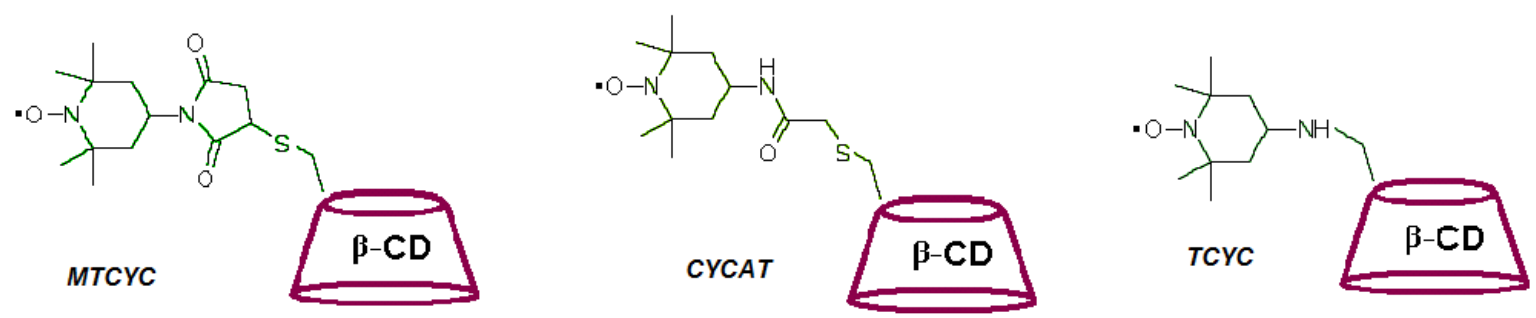

Fig. 14 - Schematic representation of mono spin-labelled $\beta$-cyclodextrins. 

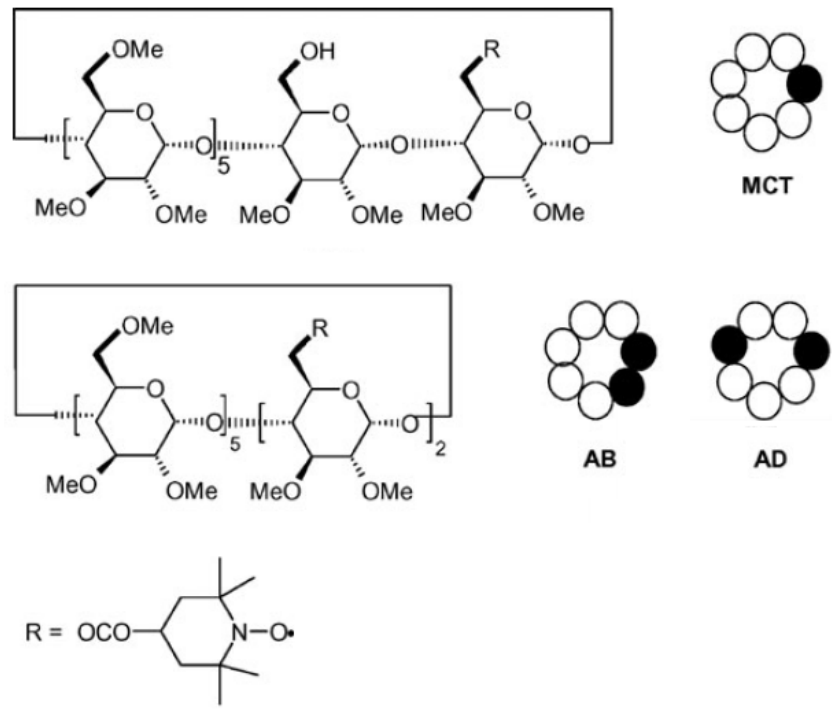

Fig. 15 - Schematic representation of mono and bis spin-labelled permethylated $\beta$-CDs.

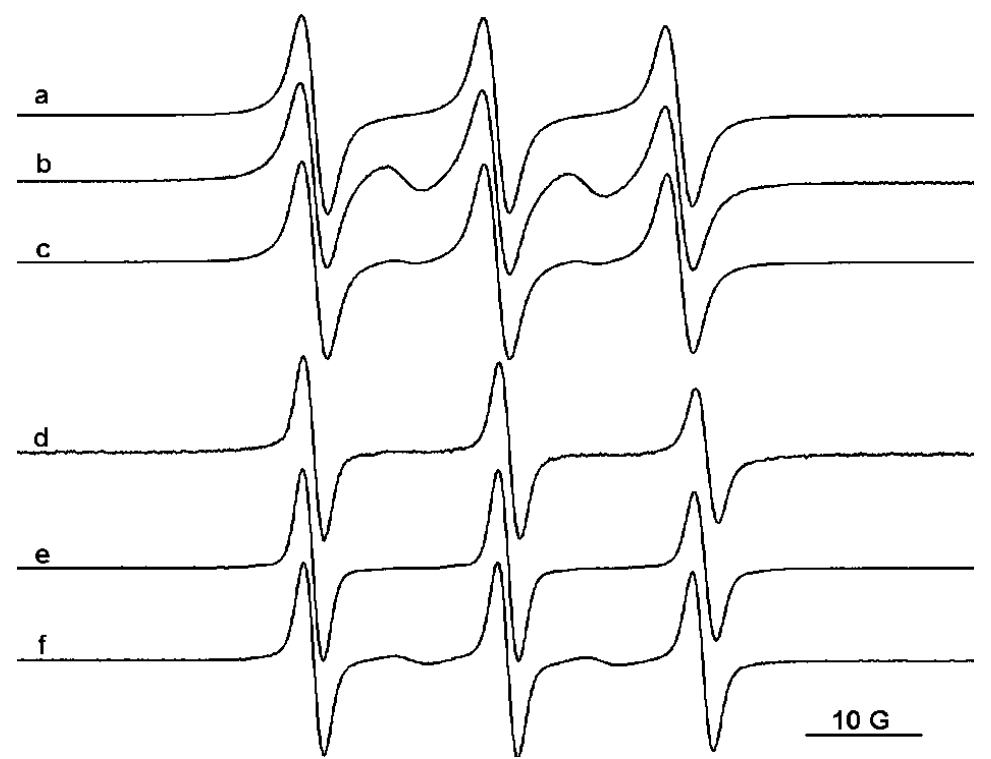

Fig. 16 - The EPR spectra of MCT (a), AB (b) and AD (c) in dichloromethane, of $\mathbf{A B}$ (d) and $\mathbf{A D}$ in water (e), and of $\mathbf{A B}$ in water at $350 \mathrm{~K}$ (f) reproduced from ref. $^{52}$

In our continuous wave EPR studies reporting on properties of SL-CDs, we have found that association constants for high affinity guests are lower compared with unfunctionalized cyclodextrins, and this has been explained assuming the self-inclusion of the spin label as a competing process. The ESEEM traces of MTCYC and TCYC spin-labelled cyclodextrins exhibit only slightly different $\mathrm{k}\left({ }^{2} \mathrm{H}\right)$ and $\mathrm{d}\left({ }^{2} \mathrm{H}\right)$ parameters compared to those of uncomplexed 4-carboxyTEMPO. Therefore, we concluded that the formation of self-inclusion complexes for MTCYC and TCYC is negligible and the nitroxide group is not shielded from the solvent. On the reverse, in the case of the spin-labelled cyclodextrin CYCAT, the self-inclusion of the paramagnetic group has been proved.

Apart from studies reporting the synthesis of mono SL-CDs, we have also reported the synthesis of two spin-labelled cyclodextrin biradicals, in which two 4-carboxy-TEMPO groups are attached to adjacent glucose units or are separated by two glucose units (Fig. 15).$^{52}$ These doubly spin-labelled cyclodextrins, denoted $\mathbf{A B}$ and $\mathbf{A D}$ (Fig. 15), were obtained by reaction of $6 \mathrm{~A}, 6 \mathrm{D}-$ and $6 \mathrm{~A}, 6 \mathrm{~B}-$ dihydroxy permethylated $\beta-C D$ with 4-carboxyTEMPO in the presence of N,N'dicyclohexylcarbodiimide. $^{56}$ Mono spin-labelled permethylated $\beta-C D$ (MCT) was also separated from the reaction mixture. Spin-spin interactions 
were observed in dichloromethane solutions of compounds $\mathbf{A B}$ and $\mathbf{A D}$, and in water solution of compound $\mathbf{A B}$ at $350 \mathrm{~K}$ (Fig. 16).

\section{Formation and properties of gels evidenced by EPR spectroscopy}

The synthesis of spin-labelled cyclodextrins opened the possibility to investigate inclusion complexes involving molecules with large molecular weight and, by extension, more complex systems. Among the latter, supramolecular gels represent a class of materials that nowadays attract the scientific interest due to their diverse applicability in fields like pharmacy, cosmetics, pollutant capture/removal and catalysis., ${ }^{5,57,58}$ Although EPR spectroscopy is not currently exploited to a large extent in this field, it can provide reliable information on the assembly of low molecular weight gelators (LMWG), on the encapsulation or diffusion of spin-labelled molecules into and from gel networks, and can be used to monitor the formation of polymeric gels. Only few studies report supramolecular gel formation based on changes in spin probe dynamics revealed by EPR spectroscopy.

Gels are classified most often considering the forces that govern the formation of the fibrillar network. Supramolecular gels result by selfassembly of LMWG molecules that generate physical gels by the formation of three-dimensional fibrous network structures as a response to various physicochemical stimuli such as heat, light, ultrasounds and chemical environments. ${ }^{59}$ As a general rule, LMWG molecules contain in their structures moieties able to generate hydrogen bonding, dipole-dipole interactions or $\pi-\pi$ interactions. The EPR studies using spin-labelling or the spin probe method have rarely been used to prove the assembly of LMFG based on the changes observed in the dynamics of the paramagnetic moiety. ${ }^{60-63}$ Starting from these literature data, we applied the EPR method to investigate the formation of supramolecular gels resulted by assembly of dibenzylidene sorbitol derivatives ${ }^{64}$ and 12hydroxystearic acid. ${ }^{65}$ The results show that our approach of using spin-labelled gelators was less sensitive compared to using spin probes like 5-doxyl stearic acid (5-DSA, Fig. 1). For our investigated systems, it seems that spin-labelled gelators cannot be integrated in the gel fibres, proving that the assembly process is highly selective.
Thermo-responsive hydrogels containing various polymeric structures have been studied by EPR spectroscopy using the spin probe method. Examples refer to thermo-responsive hydrogels of poly(N-isopropylacrylamide) $)^{16}$ and gelatin gels. ${ }^{17}$ In our group, we studied the influence of cyclodextrin on the phase transition occurring in pluronic F127 systems. ${ }^{47,66}$ For this purpose, we combined methods that offer global and local information on the systems. We used spin probes that have similar structure with F127 (spin-labelled pluronics), ${ }^{66}$ as well as dual molecular probes that allowed us to evidence which spectral method is more sensitive for studying such systems. ${ }^{47}$

Spin-labelled cyclodextrins have been used to monitor the formation of covalent gel networks resulted by crosslinking the cyclodextrin with isocyanate end-capped polyethylene oxides (Fig. 19). ${ }^{67}$ It can be observed that the crosslinking reaction in dimethylformamide (DMF) is complete when the spin-labelled $\beta$-cyclodextrin TCYC shows frozen molecular mobility.

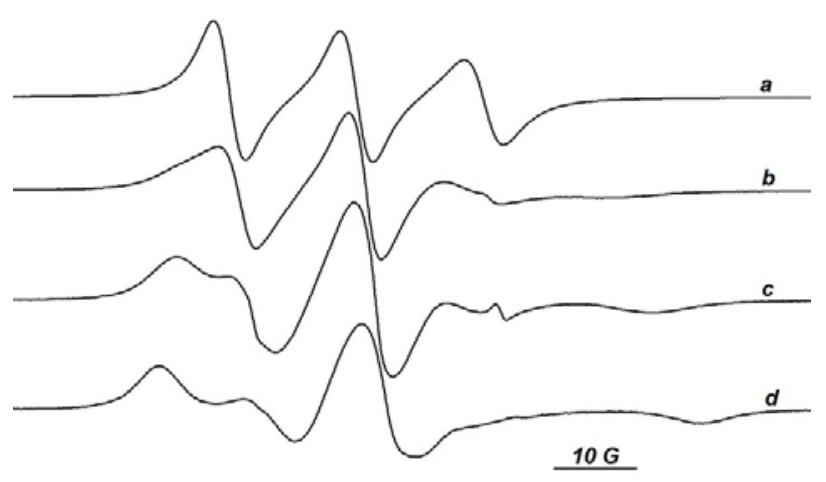

Fig. 19 - The EPR spectra of TCYC: a) in DMF, initial solution, b) during gel formation in DMF, c) after gel formation in DMF, and d) after replacing DMF with water in the gel network (reproduced from ref. ${ }^{67}$ ).

This system has been analysed in depth using EPR spectroscopy, and the results evidenced how the initial ratio of reactants influences the overall dynamics of the gel network and its absorption properties, highlighting the inhomogeneity of these polymeric gels. These gels present two regions that can accommodate various molecules, namely the cyclodextrin cavities and the solvent pools. Using spin probes, it was easy to distinguish between the two, as the probes hosted by cyclodextrins are characterised by slower dynamics, while the probes located in the solvent pools have a dynamics similar to that in solution. ${ }^{68}$ 


\section{Albumin interaction with surfactants and nanoparticles}

Albumins have remarkable affinity for hydrophobic compounds such as fatty acids and surfactants bearing hydrophobic tails, with values of the binding constants in the range $10^{6}-10^{7} \mathrm{M}^{-1}$. ${ }^{69}$ The most studied serum albumins, human (HSA) and bovine (BSA), have similar structures characterised by the existence of three helical domains. Each domain consists of a large double loop, a short connecting segment to a small double loop, a long connecting segment known as hinge to another large double loop, and a connecting segment to the next domain. These proteins present up to seven binding sites for fatty acids. ${ }^{70}$

Continuous wave and pulsed EPR spectroscopies have often been employed in the study of albumin-fatty acid interactions, as these methods provide numerical parameters of rotational motion and distances between spin probes bound to albumins. ${ }^{71}$ Studies in the literature report high affinities of doxyl spin probes for albumins, which result in a strong immobilisation of these probes in the complexes with albumins.

In our studies, instead of using doxyl-type probes, we employed the CAT16 spin probe (Fig. 1) to investigate non-covalent interactions in systems containing BSA, ionic surfactants (sodium dodecyl sulphate, SDS, or cetyl trimethyl ammonium bromide, CTAB) and/or cyclodextrin, using the spin probe method. ${ }^{72}$ The CAT16 spin probe was selected considering its structure, which consists of a hydrophobic tail, allowing interaction with the hydrophobic sites of the protein, and an ionic group, which leads to a weak interaction with the albumin while favouring a strong interaction with micelles of ionic surfactants. Using this spin probe, it was also possible to study the effect of ionic surfactants (SDS and $\mathrm{CTAB}$ ) and thermal denaturation (at $70^{\circ} \mathrm{C}$ ) on the BSA secondary structure. $^{73}$ The EPR measurements were accompanied by circular dichroism measurements in order to evidence the denaturation/renaturation effects. ${ }^{72,73}$ We have shown that ionic surfactants can be stripped from the surface of the protein by adding either cyclodextrin ${ }^{72}$ or a polymeric gel that contains cyclodextrin in the network. ${ }^{73}$ This gel can absorb the SDS molecules from the surface of albumin even at a concentration higher than the critical micelle concentration of the surfactant. From the EPR spectral analysis, it was possible to conclude that micellization of the surfactant is possible inside the solvent pools of the gel. Another study has shown that pluronic-type surfactants have little effect on the protein structure. $^{74}$

The formation and growth of gold nanoparticles in albumin solution, in the absence of a reducing agent, evidenced the two roles played by the protein, namely its reducing action on $\mathrm{Au}(\mathrm{III})$ ions and the protective role in the stabilisation of the resulting nanoparticles. The process was monitored by EPR spectroscopy using as spin probes CAT16, which has affinity for albumin, and a biradical that contains a disulphide group and thus has high affinity for gold nanoparticles. ${ }^{75}$

The EPR evidences on the interaction between fatty acid-like spin probes and albumins, and the changes of EPR parameters as a function of protein conformation can find medicinal applications. There are some studies that highlight the potential of the spin probe method of EPR spectroscopy in monitoring or even testing the cancer diagnosis. $^{76,77} \mathrm{We}$ reasoned that the EPR parameters of the spin probe 5-DSA in tear samples collected from patients with dry eye diseases can be correlated with the protein profile of the tear samples and with ophthalmic parameters. Tears contain, in small quantities, albumin and lipocalin, the latter being a prealbumin that can bind this spin probe. Although the study was performed on a small number of subjects, our results evidenced changes of the EPR spectral features during the treatment prescribed for dry eye syndrome. ${ }^{78}$

\section{CONCLUSIONS AND PERSPECTIVES}

Altogether, these studies reflect our contribution to the research on non-covalent interactions by means of EPR methods. We started investigating the bimolecular complexes resulted by interaction of host molecules with small molecule guests, then we explored more complex systems that can be relevant for biomedical and pharmaceutical applications. These are broad fields of research, and we envisage that further EPR studies on molecular reorganization processes and non-covalent assemblies will be useful for oriented applications.

\section{REFERENCES}

1. M. Lucarini and E. Mezzina, Electron Paramag. Reson., 2011, 22, 41-70. 
2. P. Franchi, M. Lucarini and G. F. Pedulli, Curr. Org. Chem., 2004, 8, 1831-1849.

3. E. G. Bagryanskaya and S. R. A. Marque, Electron Paramag. Reson., 2017, 25, 180-235.

4. J. Reichenwallner and D. Hinderberger, Biochim. Biophys. Acta Gen. Subj., 2013, 1830, 5382-5393.

5. G. Ionita, "Characterization and tailoring the properties of hydrogels using spectroscopic methods" in "Emerging Concepts in Analysis and Applications of Hydrogels', S. B. Majee (Ed.), Intech, 2016, doi:10.5772/62900.

6. A. Caragheorgheopol and H. Caldararu, Electron Paramagn. Reson., 2000, 17, 205-245.

7. A. Caragheorgheopol, A. Rogozea, R. Ganea, M. Florent and D. Goldfarb, J. Phys. Chem. C, 2010, 114, 28-35.

8. A. Caragheorgheopol, H. Caldararu, G. Ionita, F. Savonea, N. Žilková, A. Zukal and J. Čejka, Langmuir, 2005, 21, 2591-2597.

9. A. Caragheorgheopol and S. Schlick, Macromolecules, 1998, 31, 7736-7745.

10. H. Caldararu, A. Caragheorgheopol, M. Vasilescu, I. Dragutan and H. Lemmetyinen, J. Phys. Chem., 1994, 98 , 5320-5331.

11. S. Ruthstein, A. M. Raitsimring, R. Bitton, V. Frydman, A. Godt, and D. Goldfarb, Phys. Chem. Chem. Phys., 2009, 11, 148-160.

12. S. Ruthstein, J. Schmidt, E. Kesselman, Y. Talmon and D. Goldfarb, J. Am. Chem. Soc., 2006, 128, 3366-3374.

13. S. Ruthstein and D. Goldfarb, Electron Paramag. Reson., 2008, 21, 184-215.

14. M. Florent and D. Goldfarb, Micropor. Mesopor. Mat., 2012, 163, 291-299.

15. J. Martinie, J. Michon and A. Rassat, J. Am. Chem. Soc., 1975, 97, 1818-1823.

16. Y. Kotake and E. G. Janzen, Chem. Phys. Lett., 1988, 150, 199-203.

17. Y. Kotake and E. G. Janzen, J. Am. Chem. Soc., 1988, 110, 3699-3701.

18. Y. Kotake and E. G. Janzen, J. Am. Chem. Soc., 1989, 111, 2066-2070.

19. Y. Kotake and E. G. Janzen, J. Am. Chem. Soc., 1989, 111, 5138-5140.

20. Y. Kotake and E. G. Janzen, J. Am. Chem. Soc., 1992, 114, 2872-2874.

21. M. Lucarini and B. P. Roberts, Chem. Commun., 1996, 1577-1578.

22. G. Ionita, A. Caragheorgheopol, H. Caldararu, L. Jones and V. Chechik, Org. Biomol. Chem., 2009, 7, 598-602.

23. G. Ionita and V. Chechik, Phys. Chem. Chem. Phys., 2010, 12, 6956-6960.

24. G. Ionita, M. Florent, D. Goldfarb and V. Chechik, $J$. Phys. Chem. B, 2009, 113, 5781-5787.

25. G. Ionita, S. Mocanu and I. Matei, Phys. Chem. Chem. Phys., 2020, 22, 12154-12165.

26. G. Ionita, A. M. Madalan, A. M. Ariciu, A. Medvedovici and P. Ionita, New J. Chem., 2016, 40, 503-511.

27. L. C. Jones, W. M. Lackowski, Y. Vasylieva, K. Wilson and V. Chechik, Chem. Commun., 2009, 11, 1377-1379.

28. K. I. Assaf and W. M. Nau, Chem. Soc. Rev., 2015, 44, 394-418.

29. K. H. Fromming and J. Szejtli, Cyclodextrins in Pharmacy, Kluwer Academic Publishers, Dordrecht, 1994.

30. E. Mileo, C. Casati, P. Franchi, E. Mezzina and M. Lucarini, Org. Biomol. Chem., 2011, 9, 2920-2924.
31. E. Mileo, E. Mezzina, F. Grepioni, G. F. Pedulli and M. Lucarini, Chem. Eur. J., 2009, 15, 7859-7862.

32. S. Yi, B. Captain, M. F. Ottaviani and A. E. Kaifer, Langmuir, 2011, 27, 5624-5632.

33. M. V. Rekharsky and Y. Inoue, Chem. Rev., 1998, 98, 1875-1917.

34. G. Jeschke and Y. Polyhach, Phys. Chem. Chem. Phys., 2007, 9, 1895-1910.

35. G. Ionita, V. Meltzer, E. Pincu and V. Chechik, Org. Biomol. Chem., 2007, 5, 1910-1914.

36. G. Ionita, G. A. Vorobieva, V. Chechik and A. I. Kokorin, Appl. Magn. Reson., 2015, 46, 251-260.

37. G. Ionita, Rev. Roum. Chim., 2008, 53, 439-445.

38. G. I. Likhtenstein, K. Ishii and S. Nakatsuji, Photochem. Photobiol., 2007, 83, 871-881.

39. C. Coenjarts, O. Garcia, L. Llauger, J. Palfreyman, A. L.Vinette and J. C. Scaiano, J. Am. Chem. Soc., 2003, $125,620-621$.

40. E. Lozinsky, M. M. Martin, T. A. Berezina, A. I. Shames, A. L. Weis and G. I. Likhtenstein, J. Biochem. Biophys. Meth., 1999, 38, 29-42.

41. M. Vasilescu, E. Pincu, V. Meltzer and G. Ionita, New. J. Chem., 2012, 36, 2128-2134.

42. S. Mocanu, I. Matei, S. Ionescu, V. Tecuceanu, G. Marinescu, P. Ionita, D. Culita, A. Leonties and G. Ionita, Phys. Chem. Chem. Phys., 2017, 19, 27839-27847.

43. S. Mocanu, I. Matei, A. Leonties, V. Tecuceanu, A. Hanganu, Z. Minea, A. Stancu, E. I. Popescu and G. Ionita, New J. Chem., 2019, 43, 11233-11240.

44. S. Mocanu, G. Ionita and I. Matei, Spectrochim. Acta A Mol. Biomol. Spectrosc., 2020, 237, 118413.

45. S. Mocanu, G. Ionita, S. Ionescu, V. Tecuceanu, M. Enache, A. R. Leonties, C. Stavarache and I. Matei, Chem. Phys. Lett., 2018, 713, 226-234.

46. B. Zelent, J. M. Vanderkooi, R. G. Coleman, I. Gryczynski and Z. Gryczynskiy, Biophys. J., 2006, 91, 3864-3871.

47. R. Baratoiu, S. Mocanu, I. Matei, M. Bem, E. Hristea, V. Tecuceanu and G. Ionita, Macromol. Chem. Phys., 2019, 220, 1800489.

48. R. M. Paton and E. T. Kaiser, J. Am. Chem. Soc., 1970, 92, 4723-4725.

49. G. Ionita and V. Chechik, Org. Biol. Chem., 2005, 3, 3096-3098.

50. V. Chechik and G. Ionita, Org. Biomol. Chem., 2006, 4, 3505-3510.

51. D. Bardelang, A. Rockenbauer, L. Jicsinszky, J. P. Finet, H. Karoui, S. Lambert, S. R. A. Marque and P. Tordo, J. Org. Chem., 2006, 71, 7657-7667.

52. V. Chechik and G. Ionita, New J. Chem., 2007, 31, 17261729.

53. D. Bardelang, A. Rockenbauer, L. Jicsinszky, J. P. Finet, H. Karoui, S. Lambert, S. R. A. Marque and P. Tordo, J. Org. Chem., 2006, 71, 7657-7667.

54. D. Bardelang, J. P. Finet, L. Jicsinszky, H. Karoui, S. R. A. Marque, A. Rockenbauer, R. Rosas, L. Charles, V. Monnier and P. Tordo, Chem. Eur. J., 2007, 13, 93449354.

55. E. G. Bagryanskaya, D. Bardelang, S. Chenesseau, J. P. Finet, L. Jicsinszky, H. Karoui, S. R. A. Marque, K. Mobius, D. Polovyanenko, A. Savitsky and P. Tordo, Appl. Magn. Reson., 2009, 36, 181-194.

56. Z. Chen, J. S. Bradshaw, Y. F Shen, Y. Habata and M. L. Lee, J. Org. Chem., 1997, 62, 8529-8534. 
57. N. M. Sangeetha and U. Maitra, Chem. Soc. Rev., 2005, 34, 821-836.

58. P. Calvert, Adv. Mater., 2009, 21, 743-756.

59. X. Du, J. Zhou, J. Shi and B. Xu, Chem. Rev., 2015, 115, 13165-13307.

60. M. Kveder, M. Andreis, J. Makarević, M. Jokić and B. Rakvin, Chem. Phys. Lett., 2006, 420, 443-447.

61. M. Andreis, D. Caric, N. S. Vujicic, M. Jokić, M. Zinic and M. Kveder, Chem. Phys., 2012, 403, 81-88.

62. Y. Wu, Y. Hirai, Y. Tsunobuchi, H. Tokoro, H. Eimura, M. Yoshio, S. Ohkoshi and T. Kato, Chem. Sci., 2012, 3, 3007-3010.

63. A. Caragheorgheopol, W. Edwards, J. G. Hardy, D. K. Smith and V. Chechik, Langmuir, 2014, 30, 9210-9218.

64. A. M. Ariciu, T. Staicu, M. Micutz, M. V. Neacsu, P. Ionita, V. Tecuceanu, C. Munteanu and G. Ionita, Appl. Magn. Reson., 2015, 46, 1395-1407.

65. A. E. Rogozea, F. Savonea and G. Ionita, Rev. Roum. Chim., 2012, 57, 693-698.

66. M. Micutz, E. Matalon, T. Staicu, D. Angelescu, A. M. Ariciu, A. Rogozea, I. M. Turcu and G. Ionita, New J. Chem., 2014, 38, 2801-2812.

67. G. Ionita and V. Chechik, Chem. Commun., 2010, 46, $8255-8257$.

68. G. Ionita, A. M. Ariciu, O. Turcu and V. Chechik, Soft Matter, 2014, 10, 1778-1783.
69. K. Takeda and Y. Moriyama, Curr. Top. Colloid Interface Sci., 1997, 1, 109-135.

70. A. A. Bhattacharya, T. Grune and S. Curry, J. Mol. Biol., 2000, 303, 721-732.

71. J. Reichenwallner, D. Hinderberger, Biochim. Biophys. Acta, 2013, 1830, 5382-5393.

72. A. E. Rogozea, I. Matei, I. M. Turcu, G. Ionita, V. Em. Sahini, A. Salifoglou, J. Phys. Chem. B, 2012, 116, 14245-14253.

73. I. Matei, A. M. Ariciu, M. V. Neacsu, A. Collauto, A. Salifoglou and G. Ionita, J. Phys. Chem. B, 2014, 118, $11238-11252$.

74. M. V. Neacsu, I. Matei, M. Micutz, T. Staicu, A. Precupas, V. T. Popa, A. Salifoglou and G. Ionita, J. Phys. Chem. B, 2016, 120, 4258-4267.

75. I. Matei, C. M. Buta, I. M. Turcu, D. Culita, C. Munteanu and G. Ionita, Molecules, 2019, 24, 3395.

76. M. Gelos, D. Hinderberger, E. Welsing, J. Belting, K. Schnurr and B. Mann, Int. J. Colorectal Dis., 2010, 25, 119-127.

77. H. H. Haeri, J. Tomaszewski, B. Phytides, H. Schimm, G. Möslein, M. Niedergethmann, D. Hinderberger and M. Gelos, ACS Pharmacol. Transl. Sci., 2020, in press, doi.org/10.1021/acsptsci.0c00116.

78. M. M. Constantin, C. G. Corbu, C. Tanase, E. Codrici, S. Mihai, I. D. Popescu, A. M. Enciu, S. Mocanu, I. Matei, G. Ionita, Anal. Methods, 2019, 11, 965-972. 
